\title{
Metabolic Requirements during Six Minutes Walking Tests in Patients Affected by Chronic Obstructive Pulmonary Disease in Different Stages
}

\author{
Giuseppe Valerio $^{1}$, Pierluigi Bracciale ${ }^{2}$, Fabio Valerio ${ }^{3}$ \\ ${ }^{1}$ Clinica Salus Brindisi, Brindisi, Italy \\ ${ }^{2}$ Divisione di Pneumologia Ospedale "Ninetto Melli” San Pietro Vernotico, Brindisi, Italy \\ ${ }^{3}$ Università Tor Vergata Roma, Brindisi, Italy \\ Email: div.pneumo@tiscali.it
}

Received July 28, 2012; revised August 29, 2012; accepted September 10, 2012

\begin{abstract}
Backgrounds: In Chronic Obstructive Pulmonary Disease (COPD) a multi factorial effort limitation becomes progressively relevant as the disease progresses in the consecutive stages. It is measured by both six minutes walking test (6MWT) and maximal cardiopulmonary incremental test (CPET). Aim: It is important to assess in each stage of disease the metabolic load during 6MWT referring to the outcome of CPET and to ascertain whether there is a significant relationship between the measures obtained by CPET and 6MWT. Methods: Four groups of fifteen patients affected by COPD in stage I to IV underwent 6MWT and maximal CPET in the same day and results were compared to a group of healthy people. Airflow obstruction was measured by whole body plethysmography, blood gases by gas analysis, maximal oxygen consumption and metabolic parameters by ergometer, lactic acid levels by analyzer. Results: Maximal oxygen consumption $\left(\mathrm{V}^{\prime} \mathrm{O}_{2} \max \right)$ and 6MWT are progressively impaired and related $\left(\mathrm{V}^{\prime} \mathrm{O}_{2} \mathrm{max}=1.25 \pm 0.26,1.152 \pm\right.$ $0.4,1.03 \pm 0.44, .85 \pm 0.2 \mathrm{l} / \mathrm{m} ; 6 \mathrm{MWD}=452 \pm 84,446 \pm 82,381 \pm 165,200 \pm 100$ respectively in GOLD I to IV stage). Oxygen consumption $\left(\mathrm{V}^{\prime} \mathrm{O}_{2}\right)$ during 6MWT becomes stable after 3 - 4 minutes and reached at the end of the test close to those measured at decompensated metabolic acidosis anaerobic threshold (TDMA) $(85 \pm 0.4 \mathrm{l} / \mathrm{m}$ vs. $9 \pm 0.4 \mathrm{l} / \mathrm{m})$ in stage I to III, while in COPD there is no difference between $\mathrm{V}^{\prime} \mathrm{O}_{2} \max$ and $\mathrm{V}^{\prime} \mathrm{O}_{2}$ during $6 \mathrm{MWT}(0.85 \pm 0.2$ vs. $0.8 \pm$ $0.23 \mathrm{l} / \mathrm{m}) .6 \mathrm{MWT}$ is more suitable to determine oxygen desaturation than $\mathrm{CPET}\left(\mathrm{dSaO}_{2}-4 \pm 2 \%\right.$ vs. $\left.-2 \pm 1 \%\right) .6 \mathrm{MWD}$, the workload performed in $6 \mathrm{MWT}$ and $\mathrm{V}^{\prime} \mathrm{O}_{2}$ max are significantly related. Conclusion: 6MWT looks as a suitable sub maximal test related CPET. Metabolic requirements under 6MWT are close to TDMA and are obtained in a suitable, self paced, usual exercise, close to everyday experience and thus related to activity daily levels. As the disease worsens the differences between $\mathrm{V}^{\prime} \mathrm{O}_{2}$ during $6 \mathrm{MWT}$ and $\mathrm{V}^{\prime} \mathrm{O}_{2} \max$ wane.
\end{abstract}

Keywords: COPD; 6MWT; CPET; AT; TDMA

\section{Introduction}

Chronic Obstructive Pulmonary Disease (COPD) is an invalidating disease characterized by a progressive airways obstruction [1]. During the natural history of the disease there is a progressive worsening of airways obstruction, diffusing capacity, functional geometry of respiratory muscle, cardiovascular performance and peripheral muscles function leading to a multi factorial exercise limitation. The degree of exercise limitation is evaluated by the cardiopulmonary exercise test (CPET), assumed as the "gold standard" since it allows an insight into the mechanisms determining effort limitation and the measure of the maximal oxygen consumption $\left(\mathrm{V}^{\prime} \mathrm{O}_{2} \mathrm{max}\right)$, the maximal workload (Watt max or W peak), the anaerobic threshold (AT) and the decompensated metabolic acido- sis threshold (TDMA) [2,3]. CPET has several limitations since it is expensive, time consuming and potentially harmful $[2,3]$. In the clinical practice the Six-Minute Walk Test (6MWT) has replaced CPET because of the lesser requirements of time, technology and facilities and because walking is a normal activity for patients and better reflects the capacity for performing the activities of daily life than the standard exercises tests [3-6]. Lastly, the 6MWT has acquired clinical relevance since its relationship with survivability and it became one of the four domain determining the comprehensive BODE index [78]. Nevertheless the correct performance of 6MWT requires careful operative standards, such as the verbal motivation and the supervision by a skilled operator $[3,4]$. Despite its importance and widespread use, the 6MWT 
outcomeis just a measure of the distance covered in the allowed time (Six Minutes Walking Distance or 6MWD), and the operator is unaware of the physiological characteristics and of the metabolic requirements during the test whether the severity of the disease affects these features. Experimental evidences indicates that 6MWT behaves as a constant load sub-maximal exercise where the patients assumes a constant walking speed at the maximal sustainable load [6], closely related to daily activity, reaching a plateau of oxygen consumption $\left(\mathrm{V}^{\prime} \mathrm{O}_{2}\right)$ after three minutes [9]. The comparison of the outcomes of CPET as compared to $6 \mathrm{MWT}[5,10]$ shows several discrepancies: during the $6 \mathrm{MWT}$ the $\mathrm{V}^{\prime} \mathrm{O}_{2}$ may be similar to $[11,12]$ or less than $[6,13]$ that measured during the CPET, while the ventilation per minute (V'e), the carbon dioxide production $\left(\mathrm{V}^{\prime} \mathrm{CO}_{2}\right)$, the respiratory quotient (RQ) and the arterial lactate were lower [9-13] and the dyspnoea similar to or less than during CPET [6,12].The inconsistencies identified may be determined by the differences in the stages of the disease, by the small number of patients included in these studies, by the methodological issues associated with the standardisation of the 6MWT, by the different types of effort (cycling versus walking) [14].

The aim of this study was to investigate the level of the metabolic requirements under 6MWT, as compared to CPET outcomes, and if they change in the progressive stages of the disease.

\section{Methods}

\subsection{Experimental Design}

The goal to compare the metabolic requirements during incremental CPET and 6MWT was achieved by the performance of both tests in both healthy people and COPD patients. During the effort and under recovery, oxygen consumption, carbon dioxide production, ventilation (V'e), dyspnoea (D), leg fatigue (LF), cardiac frequency (CF), blood pressure (BP) were continuously measured. Lactic acid serum levels were measured under the maximum workload under CPET and at the end of 6MWT. On the same day, patients executed pulmonary function tests and effort tests. 6MWT and CPET were performed in random order, allowing a suitable time between the tests to obtain a complete recovery to baseline. The relationship between CPET and 6MWT was studied by comparing the performances and the outcomes.

\subsection{Selection of Patients}

We examined five sets, each one was composed by fifteen subjects: the former one consisted of fifteen healthy compliant non-smoking subjects used as control group, while the following ones by four groups of patients affected by COPD, diagnosed according to ATS and
GOLD statement [1], belonging to stage I to IV (according to GOLD statements). Patients were consecutively recruited as they come to observation. The biometric variables were similar between the groups (Table 1). Criteria for inclusion were: a) diagnosis of COPD, according to ATS and GOLD statements [1]; b) presence of airways obstruction (according to ATS statement and GOLD rules) with a FEV1/FVC (forced vital capacity) less than $70 \%$ after receiving $200 \mathrm{mg}$ of salbutamol; c) presence of a stable phase, checking clinical and functional parameters along one month lasting period; d) signed written informed consent; e) not smoking since at least one month; f) absence of comorbidities that would prevent the patient from performing an exercise test such as, obstructive arteriopathy, neurological or orthopaedic problems, respiratory failure requiring oxygen therapy or determining the need of sudden stops during performance of 6MWT. Patients belonging to GOLD I stage used salbutamol twice a day, in GOLD II stage inhaled salmeterol twice a day, while in GOLD stage III and IV all patients used association of salmeterol and fluthicasone and $7 / 15$ in GOLD III inhaled tiotropium as well; In stage IV $10 / 15$ in stage IV used oral theophylline, that was not assumed in the day of testing.

Table 1. Biometric and functional patterns.

\begin{tabular}{|c|c|c|c|c|c|c|}
\hline & Healthy & I & II & III & IV & Units \\
\hline Age & $62 \pm 9$ & $62 \pm 14$ & $65 \pm 8$ & $69 \pm 7$ & $69 \pm 5$ & years \\
\hline Height & $170 \pm 13$ & $168 \pm 8$ & $164 \pm 5$ & $165 \pm 8$ & $160 \pm 6$ & $\mathrm{~cm}$ \\
\hline Weight & $82 \pm 10$ & $87 \pm 13$ & $77 \pm 8$ & $78 \pm 13$ & $70 \pm 5$ & $\mathrm{kgs}$ \\
\hline Sex & $9: 6$ & $10: 5$ & 9:6 & $10: 5$ & $10: 5$ & $\mathrm{M}: \mathrm{F}$ \\
\hline $\mathrm{VC}$ & $96 \pm 11$ & $86 \pm 11$ & $68 \pm 7^{*}$ & $60 \pm 13^{*}$ & $31 \pm 8^{* *}$ & $\%$ \\
\hline FEV1 & $97 \pm 11$ & $87 \pm 7$ & $64 \pm 8^{*}$ & $44 \pm 4^{* *}$ & $27 \pm 4^{* *}$ & $\%$ \\
\hline RV & $96 \pm 14$ & $117 \pm 22$ & $123 \pm 20^{*}$ & $143 \pm 13^{*}$ & $215 \pm 46^{* *}$ & $\%$ \\
\hline $\mathrm{TlCO}$ & $95 \pm 10$ & $83 \pm 7$ & $64 \pm 14^{*}$ & $58 \pm 15^{* *}$ & $40 \pm 14^{* *}$ & $\%$ \\
\hline $\mathrm{PaO}_{2}$ & $84 \pm 10$ & $78 \pm 13$ & $78 \pm 10$ & $64 \pm 8^{*}$ & $60 \pm 13^{*}$ & $\mathrm{mmHg}$ \\
\hline $\mathrm{SaO}_{2}$ & $97 \pm 1$ & $95 \pm 3$ & $95 \pm 2$ & $93 \pm 2^{*}$ & $90 \pm 7^{*}$ & $\%$ \\
\hline $\mathrm{PaCO}_{2}$ & $40 \pm 4$ & $41 \pm 8$ & $39 \pm 5$ & $46 \pm 13^{*}$ & $49 \pm 7^{*}$ & $\mathrm{mmHg}$ \\
\hline AWR & $2.2 \pm 0.3$ & $3 \pm 1$ & $4 \pm 2$ & $8 \pm 3^{* *}$ & $10 \pm 3^{* *}$ & $\mathrm{cmH}_{2} \mathrm{O} / \mathrm{l} / \mathrm{s}$ \\
\hline ArtHyp & $4 / 15$ & $5 / 15$ & $4 / 15$ & $6 / 15$ & $6 / 15$ & $\mathrm{n}$ \\
\hline Diabet. & $3 / 15$ & $4 / 15$ & $4 / 15$ & $5 / 15$ & $4 / 15$ & $\mathrm{n}$ \\
\hline $\mathrm{n}$ & 15 & 15 & 15 & 15 & 15 & \\
\hline
\end{tabular}

$\mathrm{VC}=$ Vital capacity; FEV1 = forced expired volume in one sec.; RV = residual volume; $\mathrm{TlCO}$ = diffusion capacity for $\mathrm{CO}$ : VC, FEV1, RV, $\mathrm{TlCO}$ are expressed as \% of ERS normal standards; $\mathrm{PaO}_{2}=$ arterial oxygen tension, $\mathrm{PaCO}_{2}=$ carbon dioxide arterial tension AWR = airways resistances; mean $\pm \mathrm{s}$. d.; $*=$ difference from healthy people $(\mathrm{p}<0.05)$ $* *=\mathrm{p}<0.001 ; \mathrm{M}: \mathrm{F}=$ male:female ratio. 


\subsection{Functional Testing}

Lung volumes, expiratory flows and airways resistances were measured by whole body barometric pletismograph (Pulmolab Autobox 2000, Sensormedics, Yorba Linda, California, USA). The BODE index was computed, according to Celli [8], by measuring effort tolerance (evaluated by the MRC scale), the degree of airways obstruction (by FEV1), 6MWD and the body mass index (BMI). Gas analysis of the arterial blood obtained from the brachial artery was analysed by an automated blood gas analyser (Rapidlap 405 Bayer Health Care, FRG). Lactic acid was measured by a portable analyzer (Lactate Pro test strip, Arkray, JPN) using venous blood samples drawn at the beginning and at the end of CPET and 6MWT.

\subsection{Effort Testing}

The CPET consisted of a progressive exercise test limited by symptoms performed, according to ERS standards [3], by means of incremental test (10 Watt/min) (electromagnetic braked cycloergometer Siemens, FRG) up to the maximal tolerable workloade sustained for more than 30 seconds under verbal encouragement for the duration of the test. V'e, $\mathrm{V}^{\prime} \mathrm{O}_{2}$ and $\mathrm{V}^{\prime} \mathrm{CO}_{2}$ were obtained by a portable ergometer (Metasoft Cortex, FRG equipped with turbine spirometer, $\mathrm{CO}_{2}$ infrared analyser and polarographic Oxygen analyser). Dyspnoea and, muscle fatigue were checked by Borg scale. Oxygen saturation $\left(\mathrm{SaO}_{2}\right)$ was measured by pulsoxymeter (Nonin 8500, USA). Anaerobic threshold (AT) and the threshold of decompensated metabolic acidosis (TDMA) were identified by the "V" slope method and analysing the relationship between the ventilatory equivalents plotted versus $\mathrm{V}^{\prime} \mathrm{O}_{2}$ [3]. 6MWT was conducted, according to ATS statement [4], under careful supervision and verbal encouragement of therapist, monitoring of dyspnoea, $\mathrm{SaO}_{2}$ and muscle fatigue. The gas exchange was measured with the same instrument used under CPET. Workload performed under 6MWT was computed, according to the literature [15], by the product of the weight and 6MWD. Experimental values were referred to ERS normal standards for CPET [3] and to Enright's [16] for 6MWT.

\subsection{Statistical Analysis, Ethical Advice}

The data are expressed as means with $\pm 1 \mathrm{SD}$ in the text and tables. Statistical analysis was obtained by computer aided software (Epistat, USA) by means of unpaired $\mathrm{T}$ Student tests, comparing each group of patients to the control group. Differences between groups have been assessed by two tail Anova test. T student test and two tail Anova test allowed the comparison of the outcome between baseline and values observed during CPET at the maximal workload, the AT, the TDMA and during 6MWT. The relationship between variables was assessed by least square method analysis applied to linear fitting procedures. Differences are referred as highly significant for a "p" value less than 0.001 and significant for a " $p$ " of less than 0.05 . The Ethics Committee of our institution gave a formal authorization to the performance of the protocol before the beginning of the study. Each patient signed an informed consent. There was no conflict of interest.

\section{Results}

Biometric values were not significantly different between COPD and healthy subjects, and between COPD stages ( $p<0.5)$ (Table 1). Lung volumes showed progressive hyperinflation associated with a decrease in FEV1, $\mathrm{PaO}_{2}$ and $\mathrm{SaO}_{2}$ and increase of $\mathrm{PaCO}_{2}$. Borg index and BODE score increased significantly under stage IV, according to $\mathrm{T}$ test for unpaired values.

During CPET (Table 2), patients showed a progressive diminution of $\mathrm{V}^{\prime} \mathrm{O}_{2}$ max, maximal ventilation (V'emax), maximal workload (Watt max), threshold (AT) in the successive stages, according to $\mathrm{T}$ test for unpaired observation. V'emax and ventilatory reserve (MVV-

Table 2. Ergometric performance assessed by maximal incremental test (CPET) in COPD.

\begin{tabular}{|c|c|c|c|c|c|c|c|}
\hline & Healthy & Whole Serie & I & II & III & IV & Units \\
\hline $\mathrm{VO}_{2}$ & $1.5 \pm 0.15$ & $1.08 \pm 0.6$ & $1.25 \pm 0.26$ & $1.152 \pm 0.4$ & $1.03 \pm 0.44^{*}$ & $0.8 \pm 0.2^{*}$ & $1 / \mathrm{m}$ \\
\hline $\mathrm{CF}$ & $130 \pm 12$ & $119 \pm 12$ & $123 \pm 18$ & $121 \pm 12$ & $117 \pm 14^{*}$ & $116 \pm 8^{*}$ & bpm \\
\hline V'e & $47 \pm 7$ & $36 \pm 12$ & $40 \pm 9$ & $38 \pm 11$ & $36 \pm 11^{*}$ & $32 \pm 13^{*}$ & $1 / \mathrm{m}$ \\
\hline Watt & $152 \pm 21$ & $103 \pm 30$ & $140 \pm 48$ & $101 \pm 32^{*}$ & $88 \pm 30^{*}$ & $85 \pm 10^{*}$ & Watt \\
\hline Borg 1. f. & $3 \pm 3$ & $7 \pm 6$ & $5 \pm 3$ & $7.2 \pm 4^{*}$ & $7.8 \pm 5^{*}$ & $7.8 \pm 4^{*}$ & $\mathrm{u}$ \\
\hline $\mathrm{SaO}_{2}$ & $96 \pm 2$ & $94 \pm 10$ & $97 \pm 1$ & $95 \pm 3$ & $92 \pm 3$ & $87 \pm 4^{*}$ & $\%$ \\
\hline
\end{tabular}

$\mathrm{V}^{\prime} \mathrm{O}_{2}=$ maximal oxygen consumption; Watt $\max =\operatorname{maximal}$ load CF $\max =\operatorname{maximal}$ cardiac frequency; Borg $\mathrm{d}=\mathrm{Borg}$ dyspnoea index; Borg 1 . $\mathrm{f}$. = Borg muscular leg fatigue index; $\mathrm{SaO}_{2} 6 \mathrm{WD}=$ oxygen saturation during $6 \mathrm{MWD} ; \mathrm{SaO}_{2}=$ oxygen saturation; ${ }^{*}$ level of difference between healthy people and stage of COPD significant (less than 0.05$) ; \mathrm{x} \pm \mathrm{s}$. d. $=$ mean \pm standard deviation. 
Table 3. Ergometric performance assessed by six minutes walking distance test (6MWT).

\begin{tabular}{ccccccc}
\hline & Healthy & COPD & I & II & III & IV \\
\hline 6MWD & $563 \pm 65$ & $370 \pm 250$ & $452 \pm 84$ & $446 \pm 82$ & $381 \pm 165^{*}$ & $200 \pm 100^{*}$ \\
V'e 6MWT & $28 \pm 11$ & $26 \pm 9$ & $26 \pm 8$ & $27 \pm 10$ & $28 \pm 11$ & $24 \pm 8$ \\
VO 6 GWT & $1.1 \pm 0.3$ & $0.85 \pm 0.3$ & $0.95 \pm 0.15$ & $0.90 \pm 0.3$ & $0.82 \pm 0.4^{*}$ & $0.8 \pm 0.23^{*}$ \\
CFmax & $114 \pm 15$ & $106 \pm 15$ & $113 \pm 20$ & $104 \pm 12$ & $109 \pm 10$ & $116 \pm 16$ \\
Kgmmax & $45 \pm 5$ & $30 \pm 22$ & $41 \pm 10$ & $33 \pm 9$ & $31 \pm 14^{*}$ & $14 \pm 7^{*}$ \\
Borg d. & $2 \pm 2$ & $3.85 \pm 3$ & $2.4 \pm 2$ & $3.8 \pm 3^{*}$ & $5.2 \pm 4^{*}$ \\
Borg l.f. & $2.5 \pm 2$ & $3.35 \pm 3$ & $2.2 \pm 2$ & $3 \pm 3$ & $4.2 \pm 3^{*}$ & $4 \pm 3^{*}$ \\
SaO 2 & $96 \pm 2$ & $92 \pm 10$ & $96 \pm 3$ & $94 \pm 3$ & $90 \pm 4^{*}$ & $87 \pm 5^{*}$ \\
\hline
\end{tabular}

$\mathrm{V}^{\prime} \mathrm{O}_{2}=$ maximal oxygen consumption; Watt $\max =\operatorname{maximal}$ load; CF max = maximal cardiac frequency; Borg $\mathrm{d}=\mathrm{Borg}$ dyspnoea index; Borg 1 . f. =Borg muscular leg fatigue index; $\mathrm{SaO}_{2} 6 \mathrm{WD}=$ oxygen saturation during $6 \mathrm{MWD} ; \mathrm{SaO}_{2}=$ oxygen saturation; ${ }^{*}$ level of difference between healthy people and stage of COPD significant (less than 0.05); $\mathrm{x} \pm \mathrm{s}$. $\mathrm{d}$. = mean \pm standard deviation; units: \& MWD in mt; V'e in 1/m; V' $\mathrm{O}_{2}$ in 1/m; CF in bpm; Kgmmax in mtx $\mathrm{kg}$ $\times 1000$ Borg dispnea anf leg fatigue in units $\mathrm{SaO}_{2}$ in $\%$.

V'e) diminished progressively (V'emax = from $40 \%$ of MVV in stage I to $60 \%$ in stage IV). Maximal cardiac frequency diminished slightly while oxygen pulse $\left(\mathrm{V}^{\prime} \mathrm{O}_{2} / \mathrm{CF}\right)$ decreasd in advanced stages together with diminution of $\mathrm{SaO}_{2}$. All patients completed the test, although under stage III and IV workload tolerated was low.

During 6MWT (Table 3) patients and healthy people showed increased cardiac rate. 6MWD progressively worsened. Maximal workload tolerated showed a similar trend. Thirty percent of COPD developed also oxygen desaturation; $15 \%$ of patients, affected by more advanced airways obstruction (mainly in stages III and IV) showed tachycardia, oxygen desaturation and marked increase of Borg Dyspnea index. Dyspnoea and fatigue were significantly worst in last stages. Both in healthy people and in COPD after about three minutes a stable $\mathrm{V}^{\prime} \mathrm{O}_{2}$ was achieved during 6MWT. Under 6MWT $9 / 15$ the $\mathrm{V}^{\prime} \mathrm{O}_{2}$ measured $\left(\mathrm{V}^{\prime} \mathrm{O}_{2} 6 \mathrm{MWT}\right)$ was lower than AT observed during CPET $\left(\mathrm{V}^{\prime} \mathrm{O}_{2} \mathrm{AT}\right.$ ) (Table 4); 4/15 reached AT with requirements overlapping those measured under CPET and only $2 / 15$ of subjects reached a $\mathrm{V}^{\prime} \mathrm{O}_{2} 6 \mathrm{MWT}$ close or bigger than that measured at TDMA during CPET ( $\left.\mathrm{V}^{\prime} \mathrm{O}_{2} \mathrm{TDMA}\right)$. The comparison of the means by $\mathrm{T}$ test for paired values and of two tails variance by Anova test showed that $\mathrm{V}^{\prime} \mathrm{O}_{2} \max$ was statistically different from each other measure $(\mathrm{p}<0.001)$. The $\mathrm{V}^{\prime} \mathrm{O}_{2} 6 \mathrm{MWT}$ was not statistically different from $\mathrm{V}^{\prime} \mathrm{O}_{2} \mathrm{TDMA}$ or $\mathrm{V}^{\prime} \mathrm{O}_{2} \mathrm{AT}$ $(p=0.844)$ (no difference between columns, significant difference between rows, $\mathrm{p}=0.004$ and 0.0012 respectively) and it was significantly related to $\mathrm{V}^{\prime} \mathrm{O}_{2} \mathrm{max}, \mathrm{V}^{\prime} \mathrm{O}_{2}$ at TDMA and at AT. During COPD under stage I, 8/15 required a $\mathrm{V}^{\prime} \mathrm{O}_{2} 6 \mathrm{MWT}$ close to $\mathrm{V}^{\prime} \mathrm{O}_{2} \mathrm{AT}, 2 / 15$ between $\mathrm{V}^{\prime} \mathrm{O}_{2} \mathrm{AT}$ and $\mathrm{V}^{\prime} \mathrm{O}_{2} \mathrm{TDMA}$ and only $5 / 15$ reached or exceed $\mathrm{V}^{\prime} \mathrm{O}_{2}$ TDMA. Under stage II, $6 / 15 \mathrm{~V}^{\prime} \mathrm{O}_{2} 6 \mathrm{MWT}$ was close to $\mathrm{V}^{\prime} \mathrm{O}_{2} \mathrm{AT}$, while $3 / 15$ between $\mathrm{V}^{\prime} \mathrm{O}_{2} \mathrm{AT}$ and $\mathrm{V}^{\prime} \mathrm{O}_{2}$ TDMA and $6 / 15$ close to $\mathrm{V}^{\prime} \mathrm{O}_{2}$ TDMA. Patients in stage III showed $\mathrm{V}^{\prime} \mathrm{O}_{2} 6 \mathrm{MWT}$ lesser or close to $\mathrm{V}^{\prime} \mathrm{O}_{2} \mathrm{AT}$ in 10/15, between $\mathrm{V}^{\prime} \mathrm{O}_{2} \mathrm{AT}$ and $\mathrm{V}^{\prime} \mathrm{O}_{2}$ TDMA in $3 / 15$ and close to $\mathrm{V}^{\prime} \mathrm{O}_{2}$ TDMA in $2 / 15$. During stage IV, in $10 / 15$ $\mathrm{V}^{\prime} \mathrm{O}_{2} 6 \mathrm{MWT}$ was close to $\mathrm{V}^{\prime} \mathrm{O}_{2} \mathrm{AT}, 3 / 15$ between $\mathrm{V}^{\prime} \mathrm{O}_{2} \mathrm{AT}$ and $\mathrm{V}^{\prime} \mathrm{O}_{2}$ TDMA and $2 / 15$ close to $\mathrm{V}^{\prime} \mathrm{O}_{2} \mathrm{TDMA}$. Under stage IV, $\mathrm{V}^{\prime} \mathrm{O}_{2} 6 \mathrm{MWT}$ showed no significant difference within $\mathrm{V}^{\prime} \mathrm{O}_{2} \mathrm{AT}$ and $\mathrm{V}^{\prime} \mathrm{O}_{2}$ TDMA values both within rows ( $\mathrm{p}=0.94$ and 0.18 respectively) and columns ( 0.18 and 0.36 respectively). The mean $\mathrm{V}^{\prime} \mathrm{O}_{2} 6 \mathrm{MWT}$ was not statistically different from $\mathrm{V}^{\prime} \mathrm{O}_{2}$ TDMA and $\mathrm{V}^{\prime} \mathrm{O}_{2} \mathrm{AT}$ during CPET in stages I to III with no significant differences between columns and significant differences between rows. $\mathrm{V}^{\prime} \mathrm{O}_{2} 6 \mathrm{MWT}$ was significantly related to $\mathrm{V}^{\prime} \mathrm{O}_{2} \mathrm{TDMA}$. In healthy people the V'e and the CF reached during 6MWT were not statistically different from those measured at TDMA and AT under CPET (Tables 5-7). In COPD patients, V'e and CF during 6MWT were not different than those measured at AT or TDMA (Table 3) in stages I to III; they are not different from maximal values in stage IV. Lactate concentration was higher under walking than cycling. The comparison of values obtained under both effort procedures (Table 5) showed that oxygen desaturation is worst under walking in stages II and III, while dyspnoea and muscle fatigue under cycling. Lactic acid was doubled in $30 \%$ of patients under walking. Under both CPET and 6MWT, in stage IV there was an increased resting V'e and a reduced V'emax determining a reduced ventilatory reserve (MVV-V'e), indicating a ventilatory limit, quickly reached under effort.

\section{Discussion}

Current available data allow for the first time to assess the metabolic requirements and the effort level reached during 6MWT in healthy people and in the each stage of COPD. The most important findings of this study are the following: a) the $\mathrm{V}^{\prime} \mathrm{O}_{2}$ achieved during the $6 \mathrm{MWT}$ 
Table 4. Metabolic parameters in basal conditions, CPET and 6MWT.

\begin{tabular}{|c|c|c|c|c|c|c|c|}
\hline & & Baseline & Maximal CPET & TDMA CPET & AT CPET & $6 \mathrm{MWT}$ & Units \\
\hline \multirow[t]{4}{*}{ COPD } & $\mathrm{V}^{\prime} \mathrm{O}_{2}$ & $0.3 \pm 0.07$ & $1.08 \pm 6$ & $0.9 \pm 0.4$ & $0.78 \pm 0.4$ & $0.85 \pm 0.3$ & $1 / \mathrm{m}$ \\
\hline & $\mathrm{CF}$ & $80 \pm 11$ & $119 \pm 12$ & $115 \pm 13$ & $111 \pm 15$ & $106 \pm 15$ & bpm \\
\hline & V'e & $11 \pm 4$ & $36 \pm 12$ & $27 \pm 11$ & $23 \pm 11$ & $26 \pm 11$ & $1 / \mathrm{m}$ \\
\hline & LAT & $3.16 \pm 0.5$ & $10.7 \pm 7$ & n. a. & n. a. & $15.68 \pm 10$ & $\mathrm{mmol} / \mathrm{lt}$ \\
\hline \multirow[t]{4}{*}{ Healthy } & $\mathrm{V}^{\prime} \mathrm{O}_{2}$ & $0.27 \pm 0.05$ & $1.5 \pm 0.15$ & $1.2 \pm 0.2$ & $1.08 \pm 0.24$ & $1.09 \pm 0.3$ & $1 / \mathrm{m}$ \\
\hline & $\mathrm{CF}$ & $80 \pm 11$ & $130 \pm 12$ & $117 \pm 8$ & $105 \pm 9$ & $114 \pm 15$ & bpm \\
\hline & V'e & $9 \pm 2$ & $47 \pm 7$ & $32 \pm 6$ & $26 \pm 7$ & $29 \pm 11$ & $1 / \mathrm{m}$ \\
\hline & LAT & $3 \pm 0.3$ & $8.6 \pm 9$ & n. a. & n. a. & $12 \pm 10$ & $\mathrm{mmol} / \mathrm{lt}$ \\
\hline
\end{tabular}

LAT $=$ Lactate level; Maximal $=$ CPET maximal values; AT $=$ anaerobic threshold; TDMA $=$ decompensated metabolic acidosis threshold; $6 \mathrm{MWT}=$ $6 \mathrm{MWT}$ maximal values; AT 6MWT $=$ anaerobic threshold during $6 \mathrm{MWT} ; \mathrm{n} . \mathrm{s}$. = difference not significant; $\mathrm{n}$. a. $=$ not available; $\mathrm{n}=60$ for COPD and $\mathrm{n}=$ 15 for healthy people (health).

Table 5. Oxygen consumtion during rest, CPET (at maximum, AT and TDMA) and 6MWT.

\begin{tabular}{cccccc}
\hline & $\mathrm{V}^{\prime} \mathrm{O}_{2} \mathrm{max}$ & $\mathrm{V}^{\prime} \mathrm{O}_{2} \mathrm{TDMA}$ & $\mathrm{V}^{\prime} \mathrm{O}_{2} \mathrm{AT}$ & $\mathrm{V}^{\prime} \mathrm{O}_{2} 6 \mathrm{MWT}$ & Rest \\
\hline Healthy & $1.5 \pm 0.15^{*}$ & $1.2 \pm 0.2$ & $1.08 \pm 0.24$ & $1.09 \pm 0.3$ & $0.29 \pm 0.05^{*}$ \\
Stage I & $1.2 \pm 0.26^{*}$ & $1 \pm 0.2$ & $0.8 \pm 0.2$ & $0.91 \pm 0.15$ & $0.3 \pm 0.06^{*}$ \\
Stage II & $1.2 \pm 0.4^{*}$ & $0.98 \pm 0.3$ & $0.8 \pm 0.2$ & $0.90 \pm 0.3$ & $0.3 \pm 06^{*}$ \\
Stage III & $1.03 \pm 0.44^{*}$ & $0.86 \pm 0.33$ & $0.78 \pm 0.28$ & $0.82 \pm 0.38$ & $0.3 \pm 0.04^{*}$ \\
Stage IV & $0.85 \pm 0.2$ & $0.8 \pm 0.11$ & $0.75 \pm 0.10$ & $0.8 \pm 0.23$ & $0.3 \pm 0.08$ \\
Units & $1 / \mathrm{m}$ & $1 / \mathrm{m}$ & $1 / \mathrm{m}$ & $1 / \mathrm{m}$ & $1 / \mathrm{m}$ \\
\hline
\end{tabular}

Maximal $=$ CPET Maximal values; AT $=$ anaerobic threshold; TDMA $=$ decompensated metabolic acidosis threshold; $6 \mathrm{MWT}=6 \mathrm{MWT}$ maximal values; $*$ $=\mathrm{p}$ level of difference between values during $6 \mathrm{MWT}$ and CPET less than $0.05 ; \mathrm{V}^{\prime} \mathrm{O}_{2}=$ oxygen consumtion; V'e = minute ventilation; CF = cardiac frequency.

Table 6. Global ventilation during rest, CPET (at maximum, AT and TDMA) and 6MWT.

\begin{tabular}{|c|c|c|c|c|c|}
\hline & CPET Max & CPET TDMA & CPET AT & $6 \mathrm{MWT}$ & Rest \\
\hline Healthy & $47 \pm 7^{*}$ & $32 \pm 6$ & $26 \pm 7$ & $28 \pm 11$ & $9 \pm 1.6^{*}$ \\
\hline Stage I & $40 \pm 9^{*}$ & $27 \pm 7$ & $21 \pm 3$ & $26 \pm 8$ & $10 \pm 2$ \\
\hline Stage II & $38 \pm 11^{*}$ & $29 \pm 8$ & $25 \pm 7$ & $27 \pm 10$ & $10 \pm 3^{*}$ \\
\hline Stage III & $36 \pm 11^{*}$ & $28 \pm 8$ & $24 \pm 7$ & $28 \pm 11$ & $11 \pm 3^{*}$ \\
\hline Stage IV & $32 \pm 13^{*}$ & $25 \pm 8$ & $22 \pm 4$ & $24 \pm 8$ & $12 \pm 4^{*}$ \\
\hline Units & $1 / \mathrm{m}$ & $1 / \mathrm{m}$ & $1 / \mathrm{m}$ & $1 / \mathrm{m}$ & $1 / \mathrm{m}$ \\
\hline
\end{tabular}

Table 7. Cardiac rate during rest, CPET (at maximum, AT and TDMA) and 6MWT.

\begin{tabular}{|c|c|c|c|c|c|}
\hline & CPET Max & CPET TDMA & CPET AT & $6 \mathrm{MWT}$ & Rest \\
\hline Healthy & $130 \pm 12^{*}$ & $117 \pm 8$ & $105 \pm 9$ & $114 \pm 15$ & $80 \pm 11^{*}$ \\
\hline Stage I & $123 \pm 8^{*}$ & $116 \pm 16$ & $108 \pm 14$ & $113 \pm 20$ & $73 \pm 7$ \\
\hline Stage II & $121 \pm 12^{*}$ & $110 \pm 10$ & $103 \pm 9$ & $104 \pm 12$ & $80 \pm 7$ \\
\hline Stage III & $117 \pm 14^{*}$ & $110 \pm 11$ & $104 \pm 9$ & $109 \pm 10$ & $85 \pm 10^{*}$ \\
\hline Stage IV & $116 \pm 8^{*}$ & $111 \pm 7$ & $102 \pm 7$ & $116 \pm 16$ & $82 \pm 7^{*}$ \\
\hline Units & bpm & bpm & bpm & bpm & bpm \\
\hline
\end{tabular}


was constant after three minutes both in healthy people and in patients with COPD in stages III and IV; b) $\mathrm{V}^{\prime} \mathrm{O}_{2}$ max is an independent variable; c) 6MWD was signifycantly related with the $\mathrm{V}^{\prime} \mathrm{O}_{2} \max$ of the CPET; d) $\mathrm{V}^{\prime} \mathrm{O}_{2}$ at the end of 6MWT is very close to those measured at AT and TDMA in healthy people and in GOLD stage I to III; e) as disease progresses to stage IV the difference between $\mathrm{V}^{\prime} \mathrm{O}_{2}$ max and $\mathrm{V}^{\prime} \mathrm{O}_{2} 6 \mathrm{MWT}$ wanes; f) walking and cycling determined differences in dyspnoea, lactic acid, oxygen desaturation.

\subsection{Metabolic Load under 6MWT}

The performance and the metabolic requirements during 6MWT depend largely on several factors: a) Logistics and execution mode, such as length of corridor, speed adopted or verbal incentivation; b) subject, such as body weight, gender, lean body mass; c) degree of obstruction; d) co morbidity; e) drugs $[9,15,17,18]$.

Our data fairly agree that in healthy subjects and patients a stable state is achieved after about three minutes and that the test behaves like a constant load sub maximal test $[5-15,19]$ held at average values close to AT or TDMA in healthy people and in the patients with COPD in stages I-III. Other researchers [6] recently confirmed the same results by means of increasing speeds, indicating 6MWT as close to the maximum sustainable exercise. According to literature it is possible to appreciate that during 6MWT patients choose their usual speed walking, performing a self paced, effort limited exercise with energy requirement at the maximal sustainable workloads, close to daily life requirements [20-26]; these features explain the relationship between 6MWD and the activity daily level (ADL) or quality of life (SF36, St George's). The observed relationship between $\mathrm{V}^{\prime} \mathrm{O}_{2}$ TDMA and $\mathrm{V}^{\prime} \mathrm{O}_{2} 6 \mathrm{MWT}$ fairly agrees with the cited literature reports since the level reached express the maximal sustainable power (PMS) tolerable only for brief periods. The loss of effort power observed in the consecutive stages of COPD can be explained by the fact that the degree of obstructtion mainly determines expiratory flow limitation and hyperinflation leading to: a) reduction of inspiratory capacity; b) altered functional geometry of muscles determining the diaphragmatic excursion; c) the marked arterial oxygen desaturation; d) increase of impedance of right ventricle determining the after load; e) worsening of cardiac output allottment (diminution of the ratio between leg arterial supply versus diaphragmatic arterial supply). In very advanced stages the limitation during both CPET and 6MWT is early and sudden and associated with lactic acidosis and the $\mathrm{V}^{\prime} \mathrm{O}_{2} 6 \mathrm{MWT}$ can be similar or exceed the $\mathrm{V}^{\prime} \mathrm{O}_{2} \max$ [14]. These findings fairly agree with those observed under advanced stages of cardiac failure, interstitial pulmonary fibrosis and cystic fibrosis [27-29], where there is no difference between
$\mathrm{V}^{\prime} \mathrm{O}_{2} 6 \mathrm{MWT}$ and $\mathrm{V}^{\prime} \mathrm{O}_{2} \max$. The literature $[6,9,11,12]$ reports the same outcome: the comparison between external paced test (shuttle test) and self paced test (6MWT) shows that the differences become even smaller as the functional capacity become more limited. It is possible to explain the occurrence of $\mathrm{V}^{\prime} \mathrm{O}_{2} 6 \mathrm{MWT}$ exceeding $\mathrm{V}^{\prime} \mathrm{O}_{2}$ max assuming that walking involves more muscles of the trunk and upper limbs than cycling or in case of an inappropriate non tolerable external load imposed during cycling, causing high lactate levels and sudden stops or finally by inappropriate shortness of the corridor used leading to a marked increase in $\mathrm{V}^{\prime} \mathrm{O}_{2}$ [14]. In very advanced stages, the workload required by 6MWD exceeds the functional reserve of patients and the aerobic supply with frequent stops and recovery phases; the same happens during CPET and both tests behave as the sum of multiple brief maximal aerobic-anaerobic efforts followed by hyperventilation recovery periods, although these patients were excluded from the current study.

\subsection{Relationship between CPET and 6MWT}

The comparison of $\mathrm{V}^{\prime} \mathrm{O}_{2}$ max between CPET and 6MWT must consider the different settings, the heavier workload during cycling in patients with moderate disease, the effect of weight during walking in patients with advanced disease, the different posture and functional geometry of respiratory muscles, the more extensive involvement of muscles during walking [30]. The significant relationship between $\mathrm{V}^{\prime} \mathrm{O}_{2}$ max and 6MWD is confirmed by other authors $[14,19]$ : in patients with mild disability $\left(\mathrm{VO}_{2} \mathrm{max}\right.$ $>20 \mathrm{ml} / \mathrm{kg} / \mathrm{min}$ ) a $6 \mathrm{MWD}$ higher than $520 \mathrm{mt}$ could be expected, while in patients with moderate disease $\left(\mathrm{VO}_{2} \mathrm{max} 15-20 \mathrm{ml} / \mathrm{kg} / \mathrm{min}\right)$ the $6 \mathrm{MWD}$ was in the range 250 to $550 \mathrm{mt}$ with a mean of $420 \mathrm{mt}$. Both measures have prognostic power: a 6MWD lesser than $350 \mathrm{mt}$ a 6MWORK lesser than $5000 \mathrm{kgm}$ or a $\mathrm{V}^{\prime} \mathrm{O}_{2}$ max lesser than $15 \mathrm{ml} / \mathrm{kg} / \mathrm{min}$ are associated with poor prognosis and increased mortality [20,24]. The reported differences $[6,9,13,14]$ within metabolic or cardio respiretory outcomes between CPET and 6MWT can be explained taking into account the different levels of metabolic requirements reached in stage I-III and stage IV, the different maximal workload tolerated, the different involvement of muscular groups, the different trend over time of variables, since dyspnoea and the cardiac frequency increase linearly during effort in CPET, while in 6MWT they are constant after the $3^{\text {rd }}$ minute. Nevertheless 6MWT, although submaximal, is able to determine a worst oxygen desaturation [31] than the maximal CPET, thus rendering more suitable 6MWT in the study of diseases with effort hypoxemia, like idiopathic pulmonary fibrosis, pulmonary hypertension and COPD. Oxygen desaturation can be due to a lower ventilatory response $\left(V^{\prime} \mathrm{e} / \mathrm{V}^{\prime} \mathrm{CO}_{2}\right)$ during the walk test [32]. Both induce worsening end 
expiratory lung volumes, dynamic hyperinflation, respiretory work, increase of pulmonary artery pressure and release of oxidants load and Il6 from muscles in exerciseing wasted patients [33-35].

\subsection{Conclusion}

Literature and current data allow to appreciate that from a physiologic point of view 6MWT and the CPET, although significantly related, are not interchangeable exercise tests. Both CPET and 6MWT allow to measure the progressive effort limitation in different stages of COPD with a useful knowledge as the disease proceeds to advanced stages [13]. CPET allows to ascertain the causes underlying exercise intolerance while 6MWT is self paced and related to daily activity levels and outcomes can be improved, using a multi parametric index, expressing both 6MWD and oxygen desaturation and dyspnoea [36]. As disease worsens, the difference of metabolic requirements between 6MWT and CPET diminish. 6MWT is more suitable in diseases associated with effort-related oxygen desaturation $[13,32]$.

\section{REFERENCES}

[1] The GOLD Expert Panel, "Global Strategy for the Diagnosis and Prevention of COPD," www.goldcopd.com

[2] I. M. Weissman and R. J. Zeballos, "Modalities of Cinical Exercise Testing in Clinical Exercise Testing," In: I. M. Weisman and R. J. Zeballos, Eds., Progress in Respiratory Research, Karger, Basel, 2002, pp. 31-40.

[3] S. A. Ward and P. Palange, "Clinical Exercise Testing," European Respiratory Society Monograph, Vol. 40, 2007, pp. 108-174.

[4] R. O. Crapo, P. L. Enricht and R. J. Zeballos, "ATS Statement: Guidelines for the Six-Minutes Walk Test," American Journal of Respiratory and Critical Care Medicine, Vol. 166, No. 1, 2002, pp. 111-117.

[5] M.-L. Chuang, I.-F. Lin and K. Wasserman, "The Body Weight-Walking Distance Product as Related to Lung Function, Anaerobic Threshold and Peak $\mathrm{VO}_{2}$ in COPD Patients," Respiratory Medicine, 2001, Vol. 95, No. 7, pp. 618-626. doi:10.1053/rmed.2001.1115

[6] A. Casas, J. Vilaro, R. Rabinovich, A. Mayer, J. A. Barberà, et al., "Encouraged 6-Min Walking Test Indicates Maximum Sustainable Exercise in COPD Patients," Chest, Vol. 128, No. 1, 2005, pp. 55-61. doi:10.1378/chest.128.1.55

[7] C. G. Cote, V. Pinto-Plata, K. Kaspzzyk, et al., "The Six Minute Walking Distance, Peak Oxygen Uptake and Mortality in Chronic Obstructive Pulmonary Disease," European Respiratory Journal, Vol. 29, No. 3, 2007, pp. 535-540.

[8] B. R. Celli, C. G. Cote, J. M. Marin, C. Casanova, M. M. de Oca, R. A. Mendez, V. Pinto-Plata and H. J. Cabral, "The Body-Mass Index, Airflow Obstruction, Dyspnea and Exercise Capacity Index in Chronic Obstructive Pul- monary Disease," The New England Journal of Medicine, Vol. 350, No. 10, 2004, pp. 1005-1012

doi:10.1056/NEJMoa021322

[9] T. Troosters, J. Vilaro, R. Rabinovich, A. Casas, J. A. Barbera, R. Rodríguez-Roisin, et al., "Physiological Responses to the 6-Min Walk Test in Patients with Chronic Obstructive Pulmonary Disease," European Respiratory Journal, Vol. 20, No. 3, 2002, pp. 564-569. doi:10.1183/09031936.02.02092001

[10] S. E. Turner, P. R. Eastwood, N. M. Cecins, D. R. Hillman and S. C. Jenkins, "Physiologic Responses to Incremental and Self-Paced Exercise in COPD," Chest, Vol. 126, No. 3, 2004, pp. 766-773. doi:10.1378/chest.126.3.766

[11] C. R. Swinburn, M. Wakefield and P. W. Jones, "Performance, Ventilation, and Oxygen Consumption in Three Different Types of Exercise Test in Patients with Chronic Obstructive Lung Disease," Thorax, Vol. 40, No. 8, 1985, pp. 581-586. doi:10.1136/thx.40.8.581

[12] N. Luxton, J. A. Alison, J. Wu and M. G. Mackey, "Relationship between Field Walking Tests and Incremental Cycle Ergometry in COPD," Respirology, Vol. 13, No. 6, 2008, pp. 856-862. doi:10.1111/j.1440-1843.2008.01355.x

[13] H. A. C. van Helvoort, Y. F. Heijdra, R. C. C. de Boer, A. Swinkels, H. M. H. Thijs and P. N. R. Dekhuijzen, "Six-Minute Walking-Induced Systemic Inflammation and Oxidative Stress in Muscle-Wasted COPD Patients," Chest, Vol. 131, No. 2, 2007, pp. 439-445. doi:10.1378/chest.06-1655

[14] O. Díaz, A. Morales, R. Osses, J. Klaassen, C. Lisboa and F. Saldías, "Six-Minute-Walk Test and Maximum Exercise Test in Cycloergometer in Chronic Obstructive Pulmonary Disease. Are the Physiological Demands Equivalent?" Archivos de Bronconeumología, Vol. 46, No. 6, 2010, pp. 294-301.

[15] M.-L. Chuang, I.-F. Lin and K. Wasserman, "The Body Weight-Walking Distance Product as Related to Lung Function, Anaerobic Threshold and Peak $\mathrm{VO}_{2}$ in COPD Patients," Respiratory Medicine, Vol. 95, No. 7, 2001, pp. 618-626. doi:10.1053/rmed.2001.1115

[16] P. L. Enright, D. L. Sheril, "Reference Equations for the Six Minutes Walking Distance in Healthy Adults," American Journal of Respiratory and Critical Care Medicine, Vol. 158, No. 5, 1998, pp. 1384-1387.

[17] S. Solway, D. Brooks, et al., "A Qualitative Systematic Overview of the Measurement Properties of Functional Walk Tests Used in the Cardiorespiratory Domain," Chest, Vol. 119, No. 1, 2001, pp. 256-270. doi:10.1378/chest.119.1.256

[18] C. Incorvaia, G. C. Riario Sforza, C. Pravettoni, F. Paterniti, L. Pessina and N. Dugnani, "Assessment of Global Severity of COPD in Patients Classified by GOLD Stages Undergoing Pulmonary Rehabilitation," Multidisciplinary Respiratory Medicine, Vol. 37, No. 2, 2006, pp. 23-27.

[19] D. Starobin, M. Kramer, A. Yarmolovsky and B. Bendayan, "Assessment of Functional Capacity in Patients with Chronic Obstructive Pulmonary Disease: Correlation 
between Cardiopulmonary Exercise, 6 Minute Walk and 15 Step Exercise Oximetry Test," Israel Medical Association Journal, Vol. 8, No. 7, 2006, pp. 460-462

[20] T. Oga, K. Nishimura, M. Tsukino, et al., "Exercise Capacity Deterioration in Patients with COPD: Longitudinal Evaluation over 5 Years," Chest, Vol. 128, No. 1, 2005, pp. 62-69. doi:10.1378/chest.128.1.62

[21] T. Oga, K. Nishirnura, M. Tsukino, T. Haijro, A. Ikeda and M. Mishima, "Relationship between Different Indices of Exercise Capacity and Clinical Measures in Patients with Chronic Obstructive Pulmonary Disease," Heart \& Lung, Vol. 31, No. 5, 2002, pp. 374-381. doi:10.1067/mhl.2002.127941

[22] K. C. Ong and Y. Y. Ong, "Cardiopulmonary Exercise Testing in Patients with Chronic Obstructive Pulmonary Disease," Annals of Academy of Medicine, Singapore, Vol. 29, No. 5, 2000, pp. 648-652.

[23] R. Carter, D. B. Holiday, C. Nwasuruba, J. Stocks, C. Grothucs and B. Tiep, "6-Minute Walk Work for Assessment of Functional Capacity in Patients with COPD," Chest, Vol. 123, No. 5, 2003, pp. 1408-1415. doi:10.1378/chest.123.5.1408

[24] N. Tojo, M. Ichioka, M. Chida, et al., "Pulmonary Exercise Testing Predicts Prognosis in Patients with Chronic Obstructive Pulmonary Disease," Internal Medicine, Vol. 44, No. 1, 2005, pp. 20-25. doi:10.2169/internalmedicine.44.20

[25] K. Hill and T. E. Dolmage, "Defining the Relationship between Average Daily Expenditure and Field-Based Walking Tests and Aerobic Reserve in COPD," Chest, Vol. 141, No. 2, 2012, pp. 406-412. doi:10.1378/chest.11-0298

[26] A. W. Vaes, F. M. Franssen, N. H. Uszko-Lencer, et al., "Task-Related Oxygen Uptake during Domestic Activities of Daily Life in Patients with COPD and Healthy Elderly Subjects," Chest, Vol. 140, No. 4, 2011, pp. 970979.

[27] D. J. Lesser, M. M. Fleming, C. A. Maher, S. B. Kim, M. S. Woo and T. G. Keens, "Does the 6-Min Walk Test Correlate with the Exercise Stress Test in Children?" Pediatric Pulmonology, Vol. 45, No. 2, 2010, pp. 135-140. doi:10.1002/ppul.21125

[28] I. Blanco, C. Villaquirán, J. L. Valera, M. Molina-Molina, A. Xaubet, R. Rodríguez-Roisin, J. A. Barberà and J.
Roca, "Peak Oxygen Uptake during the Six-Minute Walk Test in Diffuse Interstitial Lung Disease and Pulmonary Hypertension," Archivos de Bronconeumología, Vol. 46, No. 3, 2010, pp. 122-128. doi:10.1016/S1579-2129(10)70032-X

[29] M. Jehn, M. Halle, T. Schuster, H. Hanssen, M. Weis, et al., "The 6-Min Walk Test in Heart Failure: Is It a Max or Sub-Maximum Exercise Test?" European Journal of Applied Physiology, Vol. 107, No. 3, 2009, pp. 317-323. doi:10.1007/s00421-009-1128-0

[30] P. Palange, S. Forte, P. Onorati, F. Manfredi, P. Serra and S. Carlone, "Ventilatory and Metabolic Adaptations to Walking and Cycling in Patients with COPD," Journal of Applied Physiology, Vol. 88, No. 5, 2000, pp. 1715-1720.

[31] M. Poulain, F. Durand, B. Palomba, F. Ceugniet, J. Desplan, A. Varray and C. Préfaut, "6-Minute Walk Testing Is More Sensitive than Maximal Incremental Cycle Testing for Detecting Oxygen Desaturation in Patients with COPD," Chest, Vol. 123, No. 5, 2003, pp. 14011407.

[32] D. Hsia, R. Casaburi, A. Pradhan, E. Torres and J. Porszasz, "Physiological Responses to Linear Treadmill and Cycle Ergometer Exercise in COPD," European Respiratory Journal, Vol. 34, No. 3, 2009, pp. 605-615. doi:10.1183/09031936.00069408

[33] A. Aliverti, N. Stevenson, R. L. Dellacà, et al., "Regional Chest Wall Volumes during Exercise in Chronic Obstructive Pulmonary Disease," Thorax, Vol. 59, No. 3, 2004, pp. 210-216. doi:10.1136/thorax.2003.011494

[34] R. Reid O. Díaz, J. Jorquera and C. Lishoa, "The Six Minute Walking Test Elicits Lung Hyperinflation in Patients with Severe Chronic Obstructive Lung Disease," Revista Médica de Chile, Vol. 129, No. 10, 2001, pp. 1171-1178.

[35] H. A. C. van Helvoort, Y. F. Heijdra, R. C. C. de Boer, et al., "Six-Minute Walking-Induced Systemic Inflammation and Oxidative Stress in Muscle-Wasted COPD Patients," Chest, Vol. 131, No. 2, 2007, pp. 439-445. doi: $10.1378 /$ chest.06-1655

[36] H. F. van Stel, J. M. Bogaard and L. H. RijssenbeekNouwens, "Multivariable Assessment of the 6-Min Walking Test in Patients with Chronic Obstructive Pulmonary Disease," American Journal of Respiratory and Critical Care Medicine, Vol. 163, No. 7, 2001, pp. 1567-1571. 